\section{Paracentric inversions: two new familial cases, inv (7)(q22q11) and inv (11)(q23q13)}

Two cases of a familial paracentric inversion are described. In the first family an inv (7)(q22q11) was found in the father and his daughter, who had acute lymphoblastic leukaemia. In the second family an inv (11) (q23q13) was present in the mother and her two sons, the oldest of whom had hypoparathyroidism. Paracentric inversions have been found only rarely in man.

In family 1, the index patient, an 11-year-old girl, was the only child of healthy, non-consanguineous parents. She was born at term after a normal pregnancy (birth weight $3750 \mathrm{~g}$ ). Growth, weight gain, and psychomotor development were normal. No congenital anomalies were present and the family history was negative. At the age of 11 years, she developed acute lymphoblastic leukaemia. Despite chemotherapy she died at the age of 16 years.

In family 2 , the index patient was a boy, the first child of healthy, non-consanguineous parents. He was born at term after a pregnancy complicated by toxicosis and raised blood pressure. Birth weight was $3800 \mathrm{~g}$. Two years after the birth of the index patient a second child, a normal boy, was born. The family history was negative.

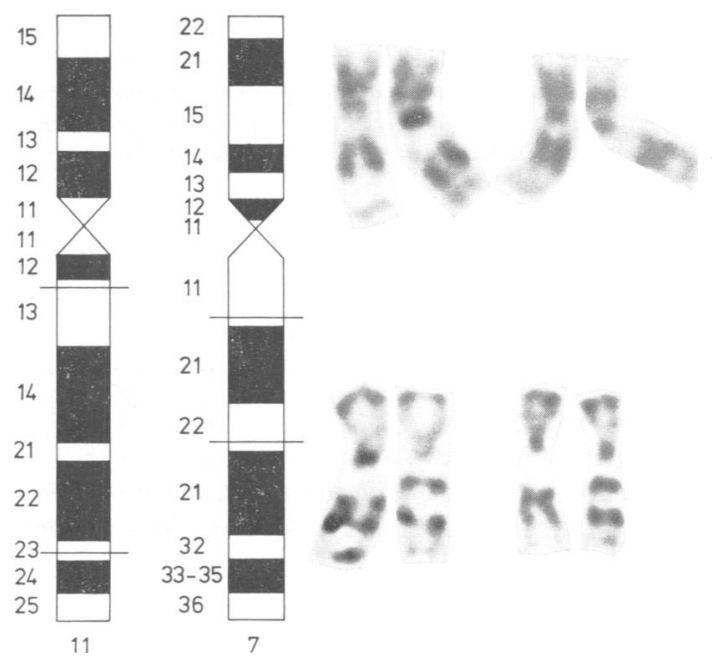

FIGURE Diagrams showing the breakpoints in chromosomes 11 and 7 with some examples of the chromosomes of the index patient of family 1 (lower row) and of the index patient of family 2 (upper row).

Received for publication 15 October 1982.

Accepted for publication 7 December 1982.
At the age of one month (length $58 \mathrm{~cm}$, head circumference $39 \mathrm{~cm}$, weight $4750 \mathrm{~g}$ ) the child was seen in our department because of seizures. At examination no congenital anomalies were seen. Neurological examination was normal. Laboratory investigations, however, revealed hypoparathyroidism, for which the child received treatment. The last time the boy was seen was at the age of 13 years. Clinical examination was completely normal. There was no psychomotor retardation and growth and weight gain were normal (height 158.5 $\mathrm{cm}$, weight $49 \mathrm{~kg}$, head circumference $57 \mathrm{~cm}$ ).

Examination of $\mathrm{G}$ banded mitoses revealed a paracentric inversion of the long arm of chromosome 7 (inv (7) (pter $\rightarrow$ q11::q22 $\rightarrow$ q11::q22 $\rightarrow$ qter)) in the index patient of family 1 and her father. The mother had normal chromosomes. In family 2 , the index patient, his mother, and his brother had a paracentric inversion of chromosome 11 (inv (11) (pter $\rightarrow$ q13:: q23 $\rightarrow$ q13::q23 $\rightarrow$ qter)) (figure). The father had normal chromosomes. No other chromosome abnormalities were present in either family.

Compared to pericentric inversions, paracentric inversions have been found very infrequently. Most of the cases known have been reviewed by Fryns and Van den Berghe. ${ }^{1}$ As far as we know, the paracentric inversion of chromosome 11 described here is probably the first case reported so far for this chromosome. However, paracentric inversions of chromosome 7 , like chromosome 3, seem to occur more frequently than in other chromosomes. ${ }^{1}$

The possible phenotypic effect of paracentric inversions is still unclear because of the few cases reported and the variability of clinical features. However, the recent findings of paracentric inversions of chromosome 3 in the blast cells of patients with acute non-lymphocytic leukaemia $^{2}$ may possibly bear some relation to our patient with acute leukaemia and a paracentric inversion of chromosome 7 .

\section{E Orye and H Van Bever \\ Laboratory of Cytogenetics, Department of Pediatrics,} Akademisch Ziekenhuis, Rijksuniversiteit Gent, Gent, Belgium.

\section{References}

1 Fryns JP, Van den Berghe $H$. Paracentric inversion in man: personal experience and review of the literature. Hum Genet 1980;54:413-6.

2 Bernstein R, Pinto MR, Behr A, Mendelow B. Chromosome 3 abnormalities in acute non-lymphocytic leukemia (ANLL) with abnormal thrombopoiesis: report of three patients with a 'new' inversion anomaly and a further case of homologous translocation. Blood 1982;60:613-7.

Correspondence and requests for reprints to Dr E Orye, Laboratory of Cytogenetics, Department of Pediatrics, Akademisch Ziekenhuis, Rijksuniversiteit Gent, De Pintelaan 185, B-9000 Gent, Belgium. 